University of Nebraska - Lincoln

DigitalCommons@University of Nebraska - Lincoln

Leadership Institute Faculty Publications

Leadership Institute

2006

Using Multiple Methods in Personality Psychology

\author{
Brent W. Roberts \\ University of Illinois at Urbana-Champaign, bwrobrts@illinois.edu \\ Peter D. Harms \\ University of Nebraska - Lincoln, pharms@gmail.com \\ Jennifer L. Smith \\ University of Illinois at Urbana-Champaign \\ Dustin Wood \\ University of Illinois at Urbana-Champaign \\ Michelle Webb \\ University of Illinois at Urbana-Champaign
}

Follow this and additional works at: https://digitalcommons.unl.edu/leadershipfacpub

Part of the Management Sciences and Quantitative Methods Commons

Roberts, Brent W.; Harms, Peter D.; Smith, Jennifer L.; Wood, Dustin; and Webb, Michelle, "Using Multiple Methods in Personality Psychology" (2006). Leadership Institute Faculty Publications. 24.

https://digitalcommons.unl.edu/leadershipfacpub/24

This Article is brought to you for free and open access by the Leadership Institute at DigitalCommons@University of Nebraska - Lincoln. It has been accepted for inclusion in Leadership Institute Faculty Publications by an authorized administrator of DigitalCommons@University of Nebraska - Lincoln. 
Published (as Chapter 22) in Michael Eid and Ed Diener, eds., Handbook of Multimethod Measurement in Psychology (Washington, D.C.: American Psychological Association, 2006), pp. 321-335. Copyright ( 2006 American Psychological Association. Used by permission. "This article may not exactly replicate the final version published in the APA edition. It is not the copy of record."

\title{
Using Multiple Methods in Personality Psychology
}

\author{
Brent W. Roberts, Peter Harms, Jennifer L. Smith, Dustin Wood, and Michelle Webb \\ University of Illinois at Urbana-Champaign
}

In many ways, Campbell and Fiske's (1959) article on multitrait-multimethod (MTMM) approaches to construct validity has stood like a Platonic ideal for personality psychologists since its publication. In the ideal study, and scientific world, our constructs should converge in a robust and coherent fashion across diverse methods. Moreover, we should all aspire to use multiple methods in both validating our measures and in investigating our ideas. Interestingly, that Platonic ideal is not realized as often as expected. If one looks closely at the empirical literature in personality psychology, the expectation that abstract constructs should converge across methods is seldom met at the level implied in the original article. This is not to argue that the Platonic ideal is not appropriate. Rather, one of the major points we would like to make in this chapter is that the ideal of the MTMM approach is often taken too literally and is sometimes misused or misinterpreted. Why speak such apostasies? In large part, because we are motivated to reiterate points made, ironically, by Fiske himself (Fiske, 1971).

What are these points? The first is that different methods, or modes as Fiske (1971) described them, are seldom innocuous. Thus, the literal assumption drawn from Campbell and Fiske (1959) that measures of similar constructs drawn from different methods should converge quite robustly is not met as often as we would like. This can lead to erroneous and nihilistic conclusions, such as the construct of interest, like depression, does not exist (e.g., Lewis, 1999). The second point is the assumption that monomethod studies are problematic, in- adequate, and should be avoided at all costs. Or, conversely, we should all be doing multimethod studies. This directive fails to consider the empirical I fact just mentioned, which is that measures of the same construct seldom correlate highly enough across methods to warrant averaging across methods (Fiske, 1971). What are needed, rather than mandates to perform multimethod studies, are theoretical models that successfully incorporate and explain both the overlap and lack thereof of identical constructs across methods. In our following review, we will attempt to highlight the few theories and empirical examples that have done so.

Our third point is that the focus on multiple methods has inadvertently led to a misguided boondoggle to search for the methodological holy grail - the one method that deserves our ultimate attention. Campbell and Fiske (1959) should not be saddled with full responsibility for this phenomenon beyond the fact that they made it clear that we should be pursuing multiple methods. Leave it to human nature that psychologists would take that idea and try to one up the multimethod approach by finding the ultimate method. Thus, we have had hyperbolic statements made for and against particular methods made since the 1960s. People have argued that self-reports are fundamentally flawed and indistinguishable from response styles (Hogan \& Nicholson, 1988; Rorer, 1965), that observer ratings are the seat of personality psychology (Hofstee, 1994), that projective tests do not work (Dawes, 1994), and that we should prioritize online measures over all other techniques (Kahn- 
eman, 1999). As will be seen in the following reviews, none of these positions is defensible.

As the methods used are often tied inextricably to the ideas in a field, we will first provide a working definition of the field of personality psychology that will serve as an organizing heuristic for the subsequent review. As will be seen, this is a true case of form following function, as the content categories within the field of personality are each dominated by specific methods. Then, we review recent multimethod studies within and across the content domains of personality psychology. We will end with some thoughts about particulars of multimethod approaches in personality psychology.

\section{WHAT IS PERSONALITY PSYCHOLOGY?}

Personality psychology is the study of the individual differences in traits, motives, abilities, and life stories that make each individual unique (Roberts \& Wood, in press). Figure 1 depicts the primary units of focus in our definition of personality, which reflects what we describe as the neosocioanalytic perspective on personality. For the purposes of this chapter, we will focus on the left-hand portion of the model and forgo a discussion of social roles and culture, so as to focus on the traditional content and methods of personality psychology. As can be seen in Figure 1 there are four "units of analysis" or domains that make up the core of personality: traits, motives, abilities, and narratives. These four domains are intended to subsume most, if not all, of the broad categories of individual differences in personality psychology.

The first domain, traits, subsumes the enduring patterns of thoughts, feelings, and behaviors that distinguish people from one another. Or, more euphemistically speaking, traits refer to what people typically think, feel, or do. In this regard, we view traits from a neo-Allportian perspective (Funder, 1991). From this perspective, traits are real, not fictions of people's semantic memory. They are causal, not just summaries of behavior. Moreover, they are learned. Even with identical genetically determined temperaments, two individuals may manifest different traits because of their unique life experiences.
Much attention has been dedicated to finding a working taxonomy of traits, and many accept the Big Five as a minimal number of domains (Goldberg, 1993). We prefer the Big Seven (Benet-Martinez \& Waller, 1997). The Big Seven adds global positive and negative evaluation to the Big Five and is a better representation of the entire trait domain. We prefer this model because, as will be seen later, one distinct characteristic of our definition of personality is the inclusion of reputation as a key element that has been underemphasized in the field. And although people may not describe themselves often with terms such as "evil" or "stunning," they do describe others in these terms.

Motivation, broadly construed, is the second domain of personality and subsumes all the things that people feel are desirable. We define the domain of motives as what people desire, need, and strive for-or perhaps more simply, what people want to do. This category includes values, interests, preferences, and goals (e.g., Holland, 1997), in addition to the classic notion of motives and needs (e.g., Murray, 1938). Currently, this domain is less coherent than the trait domain because there is no working taxonomy to organize the units of analysis. Nonetheless, there are striking commonalities across diverse areas, such as motives, goals, values, and interests. For example, in each of these domains of motivation, one can find superordinate themes of agency (desire for status and power) and communion (desire for acceptance and belonging). So, for example, the primary motivational units have been achievement, power (agency) and affiliation (communion; Smith, 1992). The higher-order factors that subsume most value dimensions also reflect power and affiliation (Schwarz \& Bless, 1992).

The third domain reflects abilities and the hierarchical models identified in achievement literatures-that is what people can do (Lubinski, 2000). Specifically, intelligence is an individual's "entire repertoire of acquired skills, knowledge, learning sets, and generalization tendencies considered intellectual in nature that [is] available at any one period of time" (Humphreys, 1984, p. 243). Two models of abilities prevail. The first decomposes generalized intelligence (g), into constituent elements of verbal, quantitative, and spatial abili- 


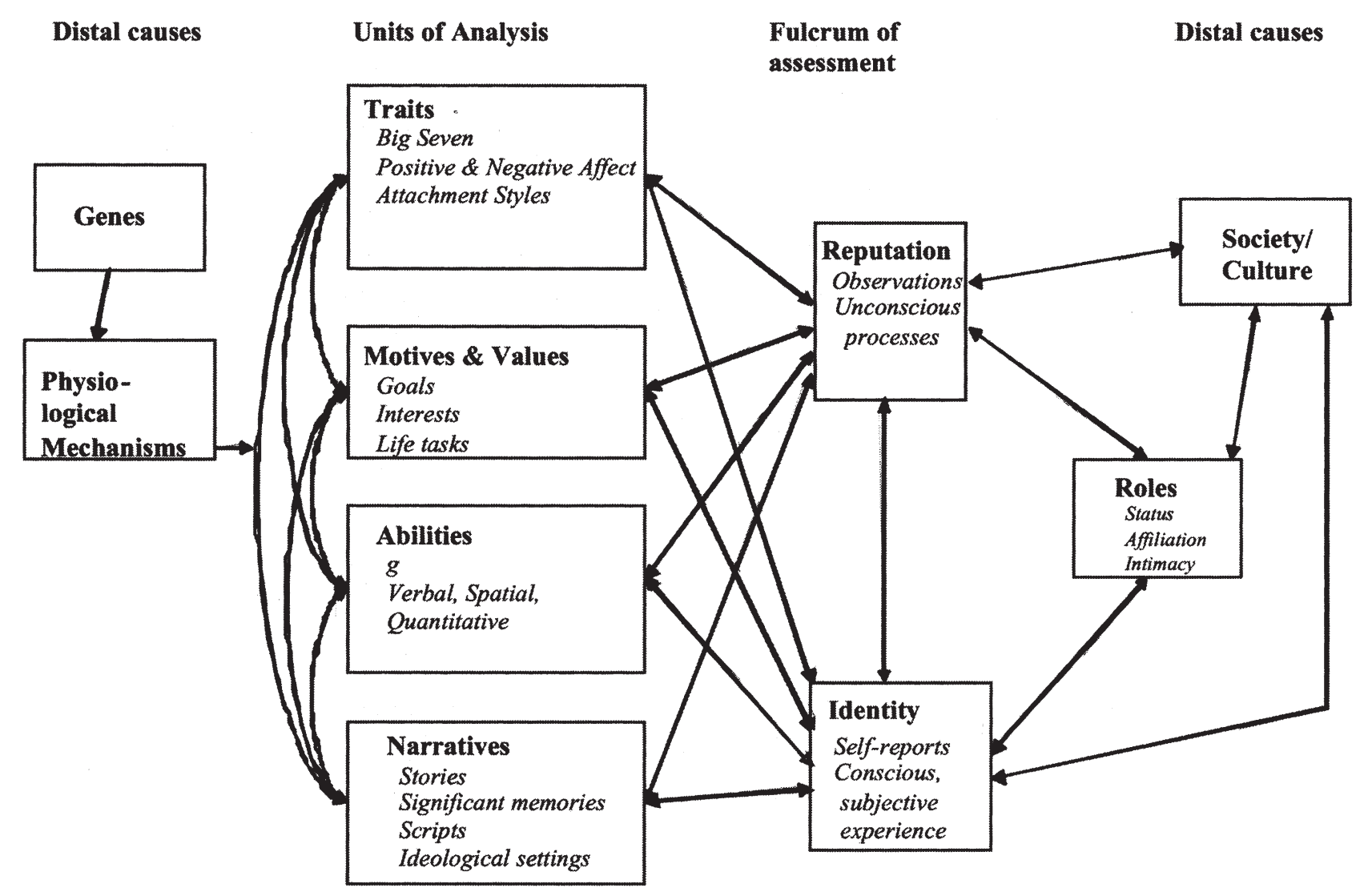

Figure 1. A neo-socioanalytic topographical model of personality psychology.

ties. The second decomposes $\mathrm{g}$ into two domains of fluid and crystallized intelligence (Horn \& Cattell, 1966). The most radical feature of our system is that individual differences in ability should be a primary focus of personality researchers. How people differ on abilities is clearly important from both pragmatic and theoretical perspectives, and any description of an individual life would be inadequate if it were not included.

The final domain focuses on the content of personal stories and narratives that people use to understand themselves and their environments (McAdams, 1993). A critical point to consider in any model of personality is that although individuals can be classified in terms of traits, abilities, and goals, they often (if not generally) communicate information about themselves quite differently than a simple nomothetic classification on these characteristics, and one common strategy is the use of illustrative stories (McAdams, 1993) or scripts (de St. Aubin, 1999). People find it very easy to tell stories about themselves, others, and their environments. These narratives in turn help people create meaning and purpose in their lives and, predictability, in the events they observe and experience and provide explanations of how people have come to be in their present circumstances.

The identification of these four domains is cursory and deserves greater attention. Nonetheless, we feel that this is a sufficient start to organizing the units of analysis found within personality psychology and, more clearly than other systems, identifies what we study and, in part, the methods we use to study individuals. 


\section{Personality Is a Multilevel Phenomenon}

A key component of our neosocioanalytic perspective on personality is that the domains of traits, motives, abilities, and narratives can be differentiated in hierarchical terms (see Hooker, 2002; Hooker \& McAdams, 2003; Mayer, 1995; Roberts \& Pomerantz, in press). For example, at the broadest level of the trait domain one finds the personality traits found in standard omnibus personality inventories. These are often the traits that make up the now ubiquitous measures of the Big Five. The midlevel of the continuum can be conceptualized by narrow traits, such as the subfacets of the Big Five (Roberts, Bogg, Walton, Chernyshenko, \& Stark, 2004). These constructs are broader than discrete behaviors but less broad than traits, as they are often constrained to specific roles and interpersonal contexts (e.g., relationships, work, and friendships). Presumably, these midlevel constructs are more stable than discrete behaviors and less stable than broad traits (e.g., Conley, 1984). At the most narrow level, we find the constituent elements of traits: thoughts, feelings, and behaviors. So, for example, one can be a depressed person, indicating a broad generalizable pattern of depressed affect across time and situation, yet experience different daily moods or states that do not correspond directly to one's trait level.

The hierarchical structuring of each domain of personality adds another layer of methods on top of the methods typically identified within personality psychology (see following). So, not only can one assess personality through global ratings of personality traits, but also through daily mood ratings or frequencies of behaviors. Or, similarly, one could assess a person's motivations through broad ratings of values and interests or the relevant actions they take in their lives, such as exercising and eating well as, manifestations of valuing health. The information gleaned from these different levels constitutes different methods that are partially overlapping, yet distinct in important ways.

\section{The Methodological and Conceptual Fulcrum: Identity and Reputation}

According to our conceptualization of personality, the components of personality are manifest in two psychological media: the identity and the reputation. Identity reflects the sum total of opinions that are cognitively available to a person across the four units of analysis described earlier. We use the term identity for several reasons. The most important reason is the fact that identity pertains to both the content of self-perceptions and the meta-cognitive perception of those same self-perceptions. Specifically, people can simultaneously see themselves as "outgoing" and a "carpenter" and feel more or less confident about those self-perceptions. Or, people can see themselves as agreeable (selfpercept) and at the same time see their agreeableness as changeable or not (meta-cognitive percept). These latter metacognitive aspects of identity, reflected in constructs such as entity versus incremental orientation (Dweck \& Leggett, 1988), identity achievement, identity clarity, and importance, play a significant role in personality assessment and development (Roberts \& Caspi, 2003).

Reputation is others' perspectives about a person's traits, motives, abilities, and narratives (Craik, 1993). There is a tendency to consider observer ratings, or in this case, reputational ratings, as higher quality than self-reports (Hofstee, 1994). This position holds some merit, as a good assessment of a person's reputation entails asking the opinion of more than one person. Thus, reputational ratings, by their very nature, are often intrinsically more reliable than self-reports because self-reports only entail the opinion of one person. Reputations also guide significant decisions, such as whether to hire a person, admit them to graduate school, marry them, or simply be their friend.

From our perspective, the self-reports used to assess identity and the observer ratings used to assess reputation both afford unique, yet flawed, information about a person. Certain psychological phenomena, such as feelings of anxiety, may best be accessed through self-reports of identity On the other hand, determining a person's true levels of agreeableness might be better assessed through the opinion of their friends and relatives who may be less defensive about another person's behavior than their own. Each perspective is potentially defective, in that neither the persons reporting on themselves nor the persons reporting on a 
friend or relative are perfectly accurate. Accepting the fact that there are two flawed and distinct ways to understand a person confronts and solves several dilemmas that have plagued personality psychology for decades. For example, it automatically incorporates the fact that people can and do attempt to manage their identity to shape their reputation. People do not always tell the whole truth about themselves to employers, friends, family, and strangers. Self-presentation is a fact in human nature and must be successfully incorporated into any theory of personality and cannot be incorporated without a distinction between identity and reputation (Hogan \& Roberts, 2000).

Despite the spirit of the MTMM approach spelled out by Campbell and Fiske (1959), the convergence of self-reports and observer ratings of personality and other phenomena has never been as high as one would hope. In most cases, the convergence averages between .3 and .6 (Funder, 1987). One of the clear conceptual and methodological advances in the field of personality psychology is the Realistic Accuracy Model (RAM; Funder, 1995), which provides a clear theoretical model identifying why identity and reputation are not more highly correlated. In this model, for a strong tie to exist between self-reports and observer ratings four conditions must hold. First, the person being perceived must do something relevant to the psychological dimension of interest. If one wants to judge whether a person is conscientious or not, then it is imperative that they act in a conscientious fashion. Second, the behavior, thought, or feeling must be displayed in a way that it is made available to the observer. Like the proverbial tree falling in an empty forest, private actions do little to influence one's reputation, unless of course they are made public. Third, the observer must detect the behavior. If the person watching does not perceive the behavior, then it might as well not have occurred. Finally, the observed act must be used in an appropriate way. For example, to some people, being clean may be a sign of conscientiousness, whereas to others it may be an indication of neuroticism (e.g., obsessiveness). The extent to which these four conditions hold determines the level of correspondence between self and observers across psychological domains.

The RAM model has implications beyond the relationship between observer/reputation and selfreports/identity. It also applies to the accuracy of self-reports themselves, in the absence of any observer data. For example, we often ask young people to rate themselves on a variety of personality dimensions without ever asking ourselves whether these individuals make good judges of their own personality. For example, a young person may be more than willing to say that they are a good leader, based not on experience but on the hope that someday they will become one (relevance). Or, quite possibly, a person may do something relevant to a trait but not notice it (detection). That is to say, people may not be aware of the importance or relevance of the diagnostic nature of their own behavior. Finally, people may use self-relevant information in idiosyncratic ways that might not conform to how scientists define or understand a nomothetically derived construct. With the exception of the availability stage of the RAM model, it seems that the remaining mechanisms for accuracy can be applied to a number of issues across psychology and personality psychology in particular.

Measures of identity and reputation also do not correlate as high as expected because they are assessed through distinct methods that afford different types of information (see Meyer et al., 2001). Clearly, identity-related assessments permit greater access to internal states and experiences that do not happen or are not visible in the company of others. Reputations, on the other hand, may be less tarnished with self-enhancement tendencies and provide a more objective profile of the information that is publicly available to people or experts (Hofstee, 1994). Reputational information may not be ideal because its validity is undermined by the fact that observers do not have complete access to a person's thoughts, feelings, and behaviors (Spain, Eaton, \& Funder, 2000), although conversely, individuals may be unaware of some of their own behavioral tendencies that impact their reputations. Using both identity and reputational information and understanding their relationship is paramount for the science of per- 
sonality. We will find that the distinction between identity and reputation runs through each of the domains of personality psychology and often acts as a fulcrum for understanding multimethod studies in personality psychology.

The methods found within the categories of identity and reputation can be further divided into the set of methods that have historically dominated the field of personality psychology. Broadly speaking, methods of assessment in personality psychology can be organized around the acronym "LOTS" (Block, 1993). L stands for life data, or the narrative content of a person's life. O stands for observer data, which can come from peers as well as trained professionals. T stands for test data and typically reflects objective performance measures. And finally, $S$ stands for self-reports, or the subjective inferences we have about ourselves. Typically, S and L data are acquired through self-report techniques of ratings or interviews. $\mathrm{T}$ and $\mathrm{O}$ data are acquired through observer reports because the tests typically have to be scored by computer or person, and observer ratings clearly must be acquired through peers, family members, or interviewers. These four approaches to assessment subsume the majority of the methodological efforts in personality psychology.

\section{MULTIPLE METHODS WITHIN THE NEOSOCIOANALYTIC FRAMEWORK OF PERSONALITY}

A more complete conceptualization of personality psychology points to many ways in which multiple methods can be brought to bear on the study of personality. First, within each domain of traits, motives, abilities, and narratives there are rich methodological traditions and differences. So, for example, traits have often been assessed using selfreports of typical behaviors. Similarly, motives and goals have been assessed from the perspective of the person (e.g., $\mathrm{S}$ data) and the psychologist who interprets a projective test such as the TAT (e.g., O data). Cognitive ability has been traditionally assessed through tests of maximal performance (e.g., $\mathrm{T}$ data), but can also be assessed via self-reports. In contrast, the narrative approach focuses on open-ended interviews, written responses, or biographical documents to understand individual differences (e.g., L data). The field of personality typically utilizes diverse methods in an attempt to understand how individuals differ from one another. This also makes studies that combine assessments from each of these disparate domains intrinsically multimethod studies. We highlight examples of these types of studies from each domain.

There are more traditional multimethod approaches within each domain of personality. For example, within the domain of personality traits, evaluating the efficacy of self-reports and observer ratings has been a constant struggle for several decades. Within the motives domain a long-standing controversy has been whether to assess motives using implicit or explicit techniques. We will highlight studies within each domain that have endeavored to use more than one method within domain.

\section{Multiple Methods and Personality Traits}

As we noted, one of the persistent disputes in personality psychology is between those who believe that self-reports or observer methods should hold priority in the field. The programmatic efforts of David Funder and his colleagues demonstrate that multiple methods bring multiple perspectives to our efforts to understand the behavioral manifestation of personality traits. For example, people judging the behaviors of others perceive different cues as more relevant to personality than the individuals themselves (Funder \& Sneed, 1993).

In other studies, the usefulness of self- and observer ratings of personality have been tested across a variety of domains, including predicting behavior, emotions, and personal negativity. The key to testing the utility of different methods is separating the perspectives of self and observer from the criterion of interest. To do this, Kolar, Funder, and Colvin (1996) set up a study in which the participants provided self-report personality ratings, close acquaintances provided an additional set of personality ratings, and the behavior of participants was coded from videotaped interactions. Thus, the two sets of predictors and criteria did not suffer from methodological overlap. For behavior in a typical social setting, such as meeting a stranger or having a discussion, observer ratings tended to predict behav- 
ior better than self-reports (Kolar, Funder, \& Colvin, 1996). For example, the correlation between self-reported tendency to initiate humor and actual behavior of initiating humor was .09. In contrast, a composite of the rating of the participants' tendency to initiate humor of two close acquaintances correlated $.23(p<.05)$ with actual behavior. Clearly, what we believe to be a joke is not perceived by others to be funny, which might explain why more people don't laugh at our jokes.

Spain et al. (2000) used a similar design to both replicate Kolar et al. (1996) and extend the design to see if self-reports might be superior in specific settings, such as when one is predicting emotion rather than behavior. Consistent with expectations, self-reported personality ratings were more strongly related to experience sampling assessments of emotion than observer ratings of personality traits. This presumably derives from the fact that emotions are internal events that are not always shared with others as overt, visible behaviors. Their private nature makes them a natural target for self-reports rather than observer ratings. Interestingly, self-reported personality ratings did better than observer ratings of personality in predicting social interactions. For example, self-reported extraversion was correlated with demonstrating social skills, as judged by a set of trained raters, whereas a composite of acquaintance ratings was essentially uncorrelated with the same behavior. In fact, for extraversion, self-reports were twice as good as observer ratings of extraversion in predicting behaviors.

Clearly, based on this research alone, we cannot make any strong generalizations about the superiority of self-reports and observer ratings of personality This is itself important, as it undermines claims that any given perspective is superior. Studies that actually use multiple methods arrive at more equivocal conclusions. This point is driven home conceptually in a review of the utility of psychological assessment (Meyer et al., 2001). In describing the importance of using multiple methods of personality assessment in clinical settings, Meyer et al. (2001) argued that each method affords a clinician, and by default a researcher, information that may not be strongly overlapping, yet still quite valid. That is to say that asking parents about a child's depression may not result in high agreement with the child's assessment (e.g., Lewis, 1999). Rather than seeing this as an indictment of either perspective or the construct of interest, we should use both of these perspectives and more (e.g., teachers, peers, siblings) to gauge the nature and progress of the phenomenon. For example, a child may have effectively hidden depression from his or her parents, but not hidden the same phenomena from his or her peers. The discrepancy itself may be both interesting and relevant to the experience of depression, as it might reflect alienation and disengagement from parents that might be a contributing factor to the depression.

The perspective that no single method holds priority extends to arguments against the use of projective measures (Dawes, 1994). For example, in our meta-analysis of the longitudinal consistency of personality trait measures (Roberts \& DelVecchio, 2000), we found that projective measures of personality traits were as consistent as observer and self-report methods of personality assessment. Moreover, in particular cases, projective measures outperform other methods, such as in the assessment of dependency (Bornstein, 1999). This does not to provide a ringing endorsement for projective tests, as it is clear that specific projective tests and particular measures derived from projective tests do not demonstrate adequate reliability and validity (Lilienfeld, Wood, \& Garb, 2000). Nonetheless, blanket statements that they should not be used are not warranted given the evidence.

The idea that perspectives that differ in terms of their hierarchical relationship to personality provide different, yet equally valid information was demonstrated nicely by a recent study of satisfaction with one's vacation (Wirtz, Kruger, NapaScollon, \& Diener, 2003). In this study, participants rated how satisfied they thought they would be with an upcoming vacation. In addition, they completed an online assessment of their emotional experiences during the vacation using experiencesampling methods. A week later, they rated how satisfied they were with their vacation. Interestingly, anticipated and retrospective ratings of satisfaction were much higher than online ratings of satisfaction, indicating a slight disjoint between 
actual experience and higher-order evaluations of that same experience. Moreover, the different methods yielded different information. The online experiences were strong predictors of the retrospective ratings of satisfaction, which were in turn the most important predictor of wanting to go on a similar vacation in the future. The effect of actual experience on the desire to go on a similar vacation was entirely mediated by the higher-order generalizations about satisfaction, which indicates that the different methods yielded complementary information rather than redundant information. This study counters the argument that online assessments should be prioritized over broader, sometimes retrospective reports of personality (e.g., Kahneman, 1999), as it was the global self-reports that predicted long-term intentions rather than direct, behavioral measures of experience.

Within the trait domain, we find many of the classic arguments about multiple methods, such as the utility of self-reports versus other ratings and newer perspectives manifest in assessing personality across multiple levels of breadth or across different contexts. Consistent with the neosocioanalytic framework that a differentiated conceptualization of personality leads to a multimethod approach, each of these different methods revealed complementary and useful information. What we still lack, of course, are theoretical systems to account for the complementary rather than overlapping nature of the information gleaned from different methods. Systems like the RAM model are a step in the right direction, but more conceptual and theoretical work is needed.

\section{Motives and Goals}

Research in the domain of motives has had two major methodological and theoretical schools, which address the study of this broader question in quite different ways. The first school, the need approach to motivation, begins with the assumption that people are often unaware of the fundamental forces that motivate their behavior. The second major school, the goal approach, attempts to understand explicit motives and interests as the means to reach a deeper, underlying understanding of motivation. Need theorists believe that mo- tivation is not accessible through conscious processes and that it should be interpreted through expert analysis of material generated by a person without their knowledge of what is being assessed. In contrast, goal theorists have no qualms about assessing goals using conscious processing.

The need approach to motivation is clearly connected historically to the use of the Thematic Apperception Test (TAT), which was initially developed by Murray (1938). Following the belief that individuals are unaware of their motives and unable to report accurately on them, the TAT was designed as a projective technique under the belief that "when a person interprets an ambiguous social situation he is apt to expose his own personality as much as the phenomenon to which he is attending" (p. 531). These observations together form the theoretical basis of the TAT, where participants are asked to take the part of story-writers and create stories on the basis of ambiguous pictures. Although the traditional TAT paradigm is the one most commonly associated with the assessment of Murray's needs, several alternative routes to the assessment of Murray's needs have been developed. For instance, Schmalt (1999) developed a "semiprojective" grid technique in which individuals are asked to rate what characters in TAT-like pictures are thinking or feeling from a fixed set of options.

The second school of thought within the domain of motivation is that of the goal approach, which begins by asking individuals what they are typically trying to do in their everyday lives. Whereas theorists working within the need approach to motivation state that behavior is determined largely by discrepancies between actual states and unconscious motives, goal theorists believe behavior is largely influenced by discrepancies that are consciously accessible (Emmons, 1986, 1989). Further, whereas needs are conceptualized as broad, decontextualized, and fundamental constructs (Winter, John, Stewart, Klohnen, \& Duncan, 1998), goals are assumed to vary hierarchically in their level of abstraction, ranging from specific and short-term goals such as "what I'm currently concerned with doing" (Klinger, 1975; Little, 1983), to more-enduring midlevel constructs such as personal strivings that reflect "what I'm typically trying to do" (Em- 
mons, 1986) and finally to more broad and longterm life goals such as establishing a career or finding a relationship partner (Roberts \& Robins, 2000). Each of these levels is associated with a slightly different method, although generally these methods are idiographic, allowing respondents to give openended responses to the instructions and rely on conscious acknowledgement of one's aspirations.

Consistent with Fiske's (1971) argument that method can have a profound effect on construct validity, one of the long-standing controversies within the field of motivation is whether implicit or explicit methods of assessing motivations assess the same constructs. McClelland, Koestner, and Weinberger (1989) argued that measures such as the TAT and questionnaire measures such as the Jackson PRF are measures of distinct constructs, labeled implicit needs and self-attributed needs, respectively. Presumably, implicit measures should predict operant behaviors that are relatively uncontrolled by the environmental, such as job level attained in organizations and behavior occurring under natural conditions (McClelland, 1980). Selfattributed motives should be more predictive of respondent behaviors, such as school grades, personality, and intelligence tests, where the behavior is elicited and constrained by environmental stimuli.

In a meta-analysis of the literature on achievement motivation comparing the utility of self-attributed ratings of motives to implicit measures of motives, Spangler (1992) found support for this hypothesis. Implicit measures were more predictive of outcomes when attaining the outcomes involved challenges or incentives that were intrinsic to the task, such as moderate risk and time pressures, whereas self-attributed measures were more predictive of performance in tasks that involved social incentives, such as challenging goals set up by the experimenter or norms that encouraged achievement. Interestingly, implicit motives were also found to decrease in their relation to task performance when the number of social incentives involved with the task was high. Consistent with the interpretation of implicit needs as somewhat akin to intrinsic motivation, Spangler suggested that social incentives may conflict or otherwise suppress the effect of implicit needs on performance.
Recently, research has attempted to form a more complete picture of the associations between motive measures by looking simultaneously at the measures used by need and goal theorists. Emmons and McAdams (1991) examined the relations between the Jackson PRF, personal strivings, and TAT measures for the assessment of the achievement, affiliation, intimacy, and power motivations. The authors found modest relations between matching TAT and striving categories for achievement, intimacy, and power motives, indicating that, to some extent, these methods may be measuring the same underlying construct. On the other hand, the self-reported PRF was related to matching dimensions of personal strivings for power and achievement measures, but was irregularly related to the TAT motives. For instance, self-reported dominance was related positively to TAT achievement, but was unrelated to TAT power. The authors concluded that personal strivings may lie somewhere between selfattributed motives and implicit motives in that strivings appeared to relate to the TAT and PRF better than these scales relate to each other.

However, a second study looking at motives for power, affiliation, and achievement (King, 1995) failed to replicate Emmons and McAdams' (1991) findings. King (1995) failed to find direct relationships between the TAT and a battery of other motive measures, including the PRF as well as strivings, reported wishes, and early memories coded using Winter's (1991) running text system. This study also failed to find relationships between the PRF and strivings measures of power or affiliation motives. The lack of relationship between the PRF and TAT motives conformed well to Spangler's (1992) finding of an average correlation between TAT and self-attributed motives of $r=.09$ across 36 studies, which suggests that implicit and self-attributed motives are not independent, but are very nearly so. Although clearly more research needs to be done, it seems reasonable to conclude from these studies that the degree of commonality between implicit and explicit methods of assessing motives is not high.

The controversy over implicit and self-attributed needs has fostered an environment in which very few researchers have combined motive measures with personality measures from the other three do- 
mains of personality (i.e., trait, ability, or narrative). In their attempt to integrate the domains of traits and motives, Winter et al. (1998) suggested that implicit motives and personality traits generally interact in their prediction of life outcomes. More specifically, they hypothesized that motives represent a person's fundamental goals and desires, whereas traits channel the expression of these motives toward specific paths. In looking at extraversion in combination with affiliation and power motivation in two samples of women, the authors found extraverts preferred volunteer work, combined family and work roles more frequently, and had more stable romantic relationships-but only if they were also high in affiliation motivation. Similarly, extraverts rated work relationships as more important than introverts, but only if they also were high in power motivation. In some cases, crossover interactions were found, where extraverts had more satisfying relationships than introverts when both were high in affiliation motivation, but the reverse was true when both were low on the motive. Winter and his colleagues had hypothesized this last interaction by considering the introverted, low-affiliation individuals as most effective at working alone and unconcerned about the opinions of others, whereas introverted high-affiliation individuals desired friendship and affection but were ineffective at maintaining it because of their awkwardness in interpersonal situations. It is interesting to note that for all of the life outcomes the authors investigated, main effects between traits and motives were rare, and the importance of the constructs would be missed if considered separately.

Although some studies exist examining the relationship between different motive measures, we found surprisingly few studies that have looked at the simultaneous interplay of motive and other personality constructs in the prediction of other outcomes. We suggest that not examining motives in combination with other domains results in a failure to fully understand the importance of motives, or worse, it may lead to erroneous conclusions about what motives are and do. For instance, early research on achievement motivation was stymied for decades by the empirical finding of negative relationships between the motive and variables such as popularity (Boyatzis, 1973). Given the current theorizing concerning trait-motive relationships, this can now be understood as a by-product of an achievement-extraversion interaction, which explains how extraverts and introverts differentially handle their level of achievement motivation (Winter et al., 1998).

The domain of motives, much like the domain of traits, is marked by the use of distinct methods that do not converge as highly as one would like. In part, this divergence is consistent with the theoretical underpinnings of the two approaches. Researchers who adopt the implicit motive approach are skeptical of cognitive appraisals of needs. In contrast, researchers who use the self-attributed approach find this less problematic. It is clear from the studies using these two approaches that they both bring independent complementary predictive variance to the research endeavor. Furthermore, when combined with methods and constructs from the trait domain, we find clear predictions of important life outcomes (Winter et al., 1998).

\section{Abilities}

Assessing intelligence has traditionally focused on multiple forms of test data ( $\mathrm{T}$ data). Standard measures of intelligence typically attempt to gather information on a wide variety of traits considered to be at the core of general mental ability. However, numerous efforts have been made to move beyond traditional assessment approaches. These have included measures of specific cognitive abilities, intellectual interests, and self-report measures of intelligence.

Testing cognitive abilities has traditionally included a variety of measurements and techniques, such as problem-solving tasks, assessments of school performance, information acquisition tasks, as well as matrix problems that require highly abstract conditional discriminations. The reason for the success in tapping general cognitive abilities using a variety of techniques largely has to do with the degree to which general mental ability permeates all learning, reasoning, and problem-solving abilities. Further, aggregations of measures of spatial skills, verbal reasoning, and quantitative abilities measure general mental ability more efficiently 
than aggregations of information items because the reasoning problems used in these measures typically capture a greater degree of common-factor variance associated with $g$ (Gustafsson, 2002). Consequently, the most popular measures of general mental ability include a variety of assessments designed to tap several broad domains highly related to general mental ability, such as verbal, quantitative, reasoning, and visuospatial skills.

The search for alternative methods of measuring general mental ability more purely has often led to the use of elementary cognitive tasks (ECTs) that measure processing speed and working memory (Jensen, 1998). These tasks highlight the hierarchical nature of intelligence and our earlier point that assessments across different levels of abstraction typically constitute related but different methods. ECTs have proved to be a popular alternative methodology for measuring general mental ability because such tasks avoid the bias that may be introduced in measurement by prior training and experience. It also is argued that basic cognitive mechanisms underlie all thinking, reasoning, and decision-making processes, and therefore such mechanisms would be substantially related to general mental ability (Kyllonen \& Christal, 1990).

Interestingly, Carroll's (1993) analysis of the structure of general mental ability showed that tasks measuring reaction time, inspection time, and discrimination ability were only weakly related to general mental ability. Indeed, early skepticism regarding the efficacy of using such measures to measure general mental ability was the result of such measures being used in isolation. However, it has been demonstrated that scores on such experimental tasks can be aggregated to form a reasonable representation of general mental ability if enough experiments are carried out across a variety of cognitive task domains (Green, 1978). It has been noted that correlations between combined reaction time scores from a number of ECTs and general mental ability approach the size typically seen with psychometric power tests (Jensen, 1998). Further, the combined scores from a number of ECTs can be used to predict upward of $70 \%$ of the heritable part of the variance in general mental ability For the purposes of experimentation, it should be noted that aggrega- tions of ECTs form two general factors, perceptual speed and working memory (Ackerman, Beier, \& Boyle, 2002). These factors are, as a result of aggregation, both highly related to general mental ability, with working memory being the more highly related to $g$ of the two (Ackerman et al., 2002).

Another approach to measuring general mental ability has been to use self-reports of intelligence or intellectual engagement (Paulhus \& Harms, 2004). This approach has been much maligned by intelligence theorists because of the fact that self-report intelligence measures rarely exceed validities of .50 with typical tests of maximal performance of cognitive ability (Paulhus, Lysy, \& Yik, 1998). Nonetheless, the search for better self-report measures has persisted because of the interest in finding a non-stressful and easily administered technique for obtaining performance information.

One of the more comprehensive and successful self-report measures of intelligence has been the Typical Intellectual Engagement (TIE) scale developed by Goff and Ackerman (1992). The premise behind this scale is that knowledge is accumulated over time through effort and motivated engagement in learning. It is therefore believed that this measure will better reflect daily behavior because it constitutes a test of typical intellectual performance. This is distinguished from a test of maximal intellectual performance, such as an SAT test, where it can be assumed that the individual is bringing their full cognitive resources to bear to succeed and attain a better outcome.

The TIE scale has been instrumental in integrating measures of the components of Ackerman's PPIK theory, a multimethod approach to understanding intellectual functioning that integrates intelligence-as-process, personality, interest, and intelligence-as-knowledge (Rolfhus \& Ackerman, 1999). By assessing each of these domains, Rolfhus and Ackerman attempted to get a better approximation of the contribution of each to scores on knowledge and intelligence tests. Participants' general mental ability was assessed using a composite of verbal, mathematical, and spatial abilities. Their personalities and interests were assessed using standard measures of the Big Five personality traits, interests, and typical intellec- 
tual engagement. Subjects also completed a battery of tests measuring their knowledge in a wide variety of domains including humanities, sciences, civics, and mechanics. This study demonstrated that a substantial higher-order Knowledge factor emerges from factor analysis of the knowledge domains that accounts for approximately $50 \%$ of the variance in domain knowledge. Further analyses showed that this general factor was significantly correlated with crystallized intelligence, which was represented by a composite of verbal ability tests. This suggests that the general knowledge factor is highly related, but not identical, to crystallized intelligence. These findings also suggest that a substantial part of the variance in knowledge test performance remains to be predicted by more domain-specific influences, such as interests and personality. For instance, Extraversion was shown to be negatively related to all but one of the domain knowledge tests, with Openness to Experience and Typical Intellectual Engagement also demonstrating significant, positive relationships across the knowledge domains. Measures of interests also proved to be related to domain knowledge scores, but were more specific with regard to matching content domains. Realistic interests were related to mechanical knowledge domains, Investigative interests were mostly related to science domains, and Artistic interests were most highly related to knowledge domains that reflected the humanities.

Like the domain of motives, one finds that combining tests of cognitive ability with measures taken from other domains, and thus other methods, maximizes our ability to predict important outcomes. One of the best multimethod studies that integrated multiple measures of intelligence, knowledge, interests, and personality measures to real-world performance outcomes was Project A (Campbell, 1985). Borman, White, Pulakos, and Oppler (1991) analyzed data from 4,362 first-term soldiers in nine U.S. Army jobs. Subjects were assessed for cognitive ability using the ASVAB, as well as job knowledge, dependability, and achievement orientation measures that were developed for the study. To assess performance, hands-on proficiency measures and supervisory ratings were taken, and the number of disciplinary actions and awards received were recorded. Path modeling demonstrated that although achievement orientation and dependability made independent, although small, contributions to supervisory ratings, the impact of general mental ability on supervisory ratings of job performance was completely mediated by job knowledge, which in turn was mediated by task proficiency. Further, dependability was positively related to job knowledge and negatively related to disciplinary actions. Achievement orientation was positively related to the number of awards a soldier received. The model demonstrated by this analysis shows that although general mental ability has a huge impact on job knowledge, and job knowledge is substantially related to task proficiency, it is by no means the largest of the contributors to job performance ratings by supervisors. Personality factors and outcomes associated with personality factors also make significant direct contributions to supervisory ratings.

There are many different approaches to the study and measurement of general mental ability. The most successful approaches, and consequently the most widely used, have used measures from across content domains to gain a fuller representation of the cognitive functioning required in reasoning, decision making, and other thought processes. Alternative approaches such as information processing techniques using elementary cognitive tasks have proved to be successful as indicators of general mental ability, but only when they are assessed and aggregated across modalities, content \&mains, and tasks. Other alternatives, such as self-report measures of intelligence and intellectual interest, have shown promise as indicators of general mental ability, but may be best suited to offering a more integrated picture of how basic brain processes, working memory, and personality may be related to real-world outcomes in intellectual functioning.

\section{Life Story Narrative as a Means of Investigating Personality}

Like the first three domains of personality, the use of narrative methods in multimethod research is a novel occurrence, yet has thus far been informative to the understanding of individual differences. Qualitative assessments of personality be- 
gin at the most basic level with the case study and progress to rigorously assessed structured interviews (McAdams, 1996, 1999). Qualitative data is frequently gathered in the form of open-ended questions concerning a topic of interest to the researcher. Consistent with the perspective that each domain of personality is arranged hierarchically, qualitative data can be examined at both the microand macrolevels. Microlevel assessment is concerned with specific linguistic patterns within the narrative such as pronoun usage or specific word type frequencies (e.g., Pennebaker \& Francis, 1996). In contrast, macrolevel assessment focuses on the broad themes throughout a narrative, such as redemption sequences (McAdams, Reynolds, Lewis, Patten, \& Bowman, 2001). Such thematic coding is often developed by the researchers after 1 listening to interviews or reading written narratives. Trained coders can then rate each qualitative datum on the varying themes of interest. Topics that are open to narrative methods are limited only by the creativity and ambition of the researcher, and the richness of the data can afford multiple opportunities to better understand the personality of an individual. For example, McAdams' life story interview (McAdams, 1996, 1999) asks people to describe low points, turning points, and religious beliefs among other experiences. Each of these stories can be examined individually for specific types of experiences (e.g., questioning of parents' religious beliefs, difficult times) to broad life-span themes, such as agency and communion. Qualitative data can thus be converted into data that is quantitatively assessable without losing the nuances of the qualitative form. Additionally, excerpts from qualitative data may be used to reiterate a theoretical point. Examples from three studies will help to illuminate these methodologies. A substantial amount of narrative research concerns the reaction of an individual to difficult life events in his or her life. Theoretically, the manner in which an individual responds to traumatic experiences that threaten his or her view of self and the surrounding world is critical for understanding the identity of that individual. If an individual is able to construct a coherent self from a difficult life event, he or she is considered to have a healthy identity.
A recent multimethod study provides a clear example of the utility of the narrative approach. Parents of children with Down syndrome were contacted through a support group mailing list as well as through area hospitals (King, Scollon, Ramsey, \& Williams, 2000). The parents were initially asked self-report questions concerning well-being, administered a projective test of ego development, and asked to write a story about when they were first told that their child had Down syndrome. Two years after the initial assessment, parents again responded to self-report measures of well-being and a projective measure of ego development. The narratives were assessed by three independent raters for themes of accommodation (exploration, shifts in perspective, activity) and closed (denial, negative affect). Parents who were low in ego development at Time 1 who wrote in an accommodative manner demonstrated increased ego development 2 years later. Parents who wrote narratives in both an accommodative and closure style had higher feelings of stress-related growth at the 2-year follow-up. This research provides an example of how healthy processing (i.e., exploring the impact of the event on the self and discovering a positive resolution about this experience) of difficult events on an individual level allows for healthier, more mature functioning later in life (King et al., 2000).

Helson (1992) examined more general identity threatening events in the writing of women's difficult life experiences in an ongoing, multimethod longitudinal study. Information was gathered about the age at which women experienced difficult, identity-changing life events and various personality factors that influenced the onset of such experiences. In addition, information about identity status (achieved, moratorium, foreclosed, and diffuse) was used to understand the meaning and effect of difficult times. Women who had a diffuse identity presented more themes related to negative evaluations of themselves. Foreclosed women wrote mainly about having bad partners or overload. Achieved/moratorium women wrote primarily about becoming psychologically independent and its consequences. Additionally, as women's vulnerability began to decrease and confidence began to increase on personality measures around 30 
years of age, an increase in identity themes occurs. This research suggests that the rewriting of the life story occurs in middle age for women, and that this is associated with an increased importance of independence, which is in turn related to healthy identity functioning.

Pals (2005) combined the narratives of the women in the Mills study with themes parallel to those of King et al. (2000) to illustrate not only the correlation between personality on the trait level and narrative level, but also the dynamic interactive processes of trait and narrative conceptualizations of personality Narratives from women who had participated in the longitudinal study described earlier (Helson, 1992) were coded for themes of resolution (overall resolution, positive ending, low negative ending, low lasting wounds, coherent ending) and impact on self (open response, narrative complexity, low self-distancing, acknowledged wounds, positive self-transformation, and active approach). These two dimensions were then used in conjunction with age 21 and age 52 responses to personality measures of open versus defensive coping (a combination of tolerance of ambiguity and reverse scored repression) and egoresiliency to predict physical and psychological health outcomes at age 61. Findings demonstrated that whereas coping openness at age 21 was related to clinician-rated maturity at age 61 , this relation was mediated by the extent to which women composed a narrative that was open to expressing the impact of the negative events on the self. Further, whereas a resolved narrative was related to subjective well-being at age 61 , this effect was mediated by ego resiliency at ages 21 and 52, suggesting a dynamic interaction of trait and narrative personality in relation to healthy functioning.

Qualitative research provides the researcher with an ability to not only examine the individual, but also the world in which the individual exists and the events that precipitate change in the individual, thus providing a complex and invaluable source of data for understanding the person as a whole. Used in combination with other methods, it is clear that narrative data can not only add a deeper, more complex understanding of basic psychological phenomena, but also account for im- portant variance in addition to standard methods, such as self-reported personality traits.

\section{CONCLUSION}

It is clear from our review that the field of personality psychology is intrinsically a multimethod field. Within and across each domain of personality, methods as diverse as self-reports, observer ratings, projective tests, test of maximal performance, and qualitative interpretations of narratives are brought to bear on understanding individual differences in thoughts, feelings, and behaviors. Consistent with our neosocioanalytic framework, many of the methods correlate quite strongly with content. Self-reports and observer ratings tend to be used more often in the assessment of personality traits, and the complement of hierarchically related constructs such as affect and behavior. The use of projective tests bridges domains, but is primarily located in the assessment of motives. Tests of maximal performance have the potential to bridge domains, but are similarly found almost entirely in the content domain of abilities. Finally, one's story is almost exclusively the domain of methods that focus on life data. Moreover, within each domain researchers are beginning to use multiple methods to assess the hierarchically related constructs within a content category, such as when broad trait measures are combined with the assessment of daily mood or behavior (e.g., Wirtz et al., 2003).

Despite the impressive methodological plurality across and within domains in personality psychology, there remains a tremendous unrealized potential to bring multiple methods to bear on relevant topics. For example, the use of test data in domains other than abilities remains untapped, despite provocative studies pointing to the potential to assess personality traits in ways other than asking someone to rate themselves on a personality inventory. Experimental tests, such as the "go, no-go" task in which people are told to inhibit a response to a cue when a stop signal tone is emitted have systematic relationships to personality traits such as impulse control (Logan, Schachar, \& Tannock, 1997) and related forms of psychopathology, such as delinquency (Mezzacappa, Kindlon, \& Earls, 2001). 
The interesting question that is as yet untested is whether tests like these can be aggregated into a reliable index of individual differences in personality traits, just as the elementary cognitive tasks have been aggregated to tap into cognitive ability.

Despite the examples cited earlier, it remains anomalous for researchers to use more than one method to investigate almost any phenomena in personality psychology. Too much time and effort have gone into reifying one or another technique as the gold standard method for assessing construct such as traits (e.g., Hofstee, 1994) or motives (McClelland et al., 1989). Also, there is a tendency to approach method variance as if it is uninteresting and an expectation that it should not play a role in the type of information gleaned from an assessment (cf. Ozer, 1986). This somewhat disrespectful approach to multiple methods quite possibly derives from the article that inspired this book (e.g., Cronbach \& Gleser, 1953), in which the construct of interest is supposed to supersede the method and therefore converge in a robust fashion across diverse techniques of assessment. In contrast, more realistic appraisals of the information taken from multiple methods point to a more sobering conclusion that the information acquired from multiple methods may in fact be more independent than previously expected (Fiske, 1971; Meyer et al., 2001; Ozer, 1986). Therefore, different methods of assessment provide complementary information rather than perfectly overlapping information. This only reinforces the point that researchers should use multiple methods in personality psychology by default to arrive at a more complete understanding of their research interests, whether it is traits, motives, abilities, or life narratives.

\section{REFERENCES}

Ackerman, P. L., Beier, M. E., \& Boyle, M. O. (2002). Individual differences in working memory within anomological network of cognitive and perceptual speed abilities. Journal of Experimental Psychology: General, 131, 567-589.

Benet-Martinex, V., \& Waller, N. G. (1997). Further evidence for the cross-culture generality of the Big Seven Factor model: Indigenous and imported Spanish personality constructs. Journal of Personality, 65, 567-598.
Block, J. (1993). Studying personality the long way. In D. C. Funder \& R. D. Parke (Eds.), Studying lives though time: Personality and development (pp. 9-41). Washington. DC: APA science volumes.

Borman, W., Whatie, L., Pulakos, E., \& Oppler, S. (1991). Models of supervisory performance ratings. Journal of Applied Psychology, 76, 863-872.

Bornstein, R. F. (1991). Criterion validity of objective and projective dependency tests: A meta-analytic assessment of behavioral prediction. Psychological Assessment, 11, 48-57.

Boyatzis, R. E. (1973). Affiliation motivation. In D. C. McClelland \& R. S. Steele (Eds.), Human motivation: A book of readings (pp. 252-275). Morristown, NJ: General Learning Press.

Campbell, D. T., \& Fiske, D. W. (1959). Convergent and discriminant validation by the multitrait-multimthod matrix. Psychological Bulletin, 56, 81-105.

Campbell, J. P. (1985). Improving the selection, classification, and utilization of Army enlisted personnel: Annual report, 1985 fiscal year (Tech. Rep. NO. 746). Alexanderia, VA: U.S. Army Research Institute for the Behavioral and Social Science.

Carroll, J. B. (1993). Human cognitive abilities: A survey of factor-analytic studies. Cambridge, England: Cambridge University Press.

Conley, J. J. (1984). The hierarchy of consistency: A review and model of longitudinal findings on adult individual differences in intelligence, personality, and self-opinion. Personality and Individual Differences, 5, 11-26.

Craik, K. H. (1993). Accentuated, revealed, and quotidian personalities. Psychological Inquiry, 4, 278-281.

Cronbach, L. J., \& Gleser, G. C. (1953). Assessing similarity between profiles. Psychological Bulletin, 50, 456473.

Dawes, R. M. (1994). House of cards: Psychology and psychotherapy built on myth. New York: The Free Press.

de St. Aubin, E. (1999). Personal ideology: The intersection of personality and religious beliefs. Journal of Personality, 67, 1105-1139.

Dweck, C. S., \& Leggett, E. L. (1988). A social-cognitive approach to motivation and personality. Psychological Review, 95, 256-273.

Emmons, R.A., \& McAdams, D. P. (1991). Personal strivings and motive dispositions: Exploring the links. Personality and Social Psychology Bulletin, 17, 648-654.

Emmons, R. A. (1986). Personal strivings: An approach to personality and subjective well-being. Journal of Personality and Social Psychology, 51, 1058-1068.

Emmons, R. A. (1989). The personal striving approach to personality. In L. A. Pervin (Ed.), Goal concepts in 
personality and social psychology (pp. 87-126). Hillsdale, NJ: Lawrence Erlbaum Associates.

Fiske, D. W. (1971). Measuring the concepts of personality. Chicago: Aldine-Atherton.

Funder, D. C. (1987). Errors and mistakes: Evaluating the accuracy of social judgment. Psychological Bulletin, 101, 75-90.

Funder, D. C. (1991). Global traits: A neo-Allportian approach to personality. Psychological Science, 2, 31-39.

Funder, D. C. (1995). On the accuracy of personality judgment: A realistic approach. Psychological Review, 102, 652-670.

Goff, M., \& Ackerman, P. L. (1992). Personality-intelligence relations: Assessment of typical intellectual engagement. Journal of Educational Psychology, 84, 537552.

Goldberg, L. R. (1993). The structure of phenotypic personality traits. American psychologist, 48, 26-34.

Green, B. F. (1978). In defense of measurement. American Psychologist, 33, 664-670.

Gustafsson, J. E. (2002). Measurement from a hierarchical point of view. In H. L. Braun, D. G. Jackson, \& D. E. Wiley (Eds.), The role of constructs in psychological and educational measurements (pp. 73-95). Mahwah, NJ: Lawrence Erlbaum Associates.

Helson, R. (1992). Women's difficult times and the rewriting of the life story. Psychology of Women Quarterly, 16, 331-347.

Hofstee, W. K. B. (1994). Who should own the definition of personality? European Journal of Personality, 8, 149162.

Hogan, R. T., \& Nicholson, R. A. (1988). The meaning of personality test scores. American Psychologist, 43, 621626.

Hogan, R. T., \& Roberts, B. W. (2000). A socioanalytic perspective on person/environment interaction. In W. B. Walsh, K. H. Craik, \& R. H. Price (Eds.), New directions in person-environment psychology (pp. 1-24). Mahwah, NJ: Lawrence Erlbaum Associates.

Holland, J. L. (1997). Making vocational choices: A theory of vocational personalities and work environments ( $3^{\text {rd }} \mathrm{ed}$.). Lutz, FL: Psychological Assessment Resources.

Hooker, K., \& McAdams, D. P. (2003). New directions in aging research: Personality reconsidered. The Journal of Gerontology: Psychological Sciences, 58, P296-P304.

Hooker, K. (2002). New directions for research in personality and aging: A comprehensive model for linking level, structure, and processes. Journal of Research in Personality, 36, 318-334.

Horn, J. L., \& Cattell, R. B. (1966). Refinement and test of the theory of fluid and crystallized general intelligences. Journal of Educational Psychology, 57, 253-270.
Humphreys, L. G. (1984). General intelligence. In C. R. Reynolds \& R. T. Brown (Eds.), Perspectives on bias in mental testing. New York: Plenum.

Jensen, A. R. (1988). The $g$ factor. Westport, CT: Praeger.

Kahneman, D. (1999). Objective happiness. In D. Kahneman \& E. Diener (Eds.), Well-being: The foundations of hedonic psychology (pp. 3-25). New York: Russell Sage Foundation.

King, L.A. (1995). Wishes, motives, goals, and personal memories: Relations of measures of human motivation. Journal of Personality, 63, 985-1007.

King, L. A., Scollon, C. K., Ramsey, C., \& Williams, T. (2000.) Stories of life transition: Subjective well-being and ego development in parents of children with Down syndrome. Journal of Research in Personality, 34, 509-536.

Klinger, E. (1975). Consequences of commitment to and disengagement from incentives. Psychological Review, 82, 223-231.

Kolar, D. W., Funder, D. C., \& Colvin C. R. (1996). Comparing the accuracy of personality judgments by the self and knowledgeable other. Journal of Personality, 64, 311-337.

Kyllonen, P. C., \& Christal, R. E. (1990). Reasoning ability is (little more than) working memory capacity?! Intelligence, 14, 389-433.

Lewis, M. (1999). On the development of personality. In L. A. Pervin \& O. P. Johns (Eds.), Handbook of personality theory and research ( $2^{\text {nd }}$ ed., pp. 327-346). New York: The Guilford Press.

Lilienfeld, S. O., Wood, J. M., \& Garb, H. N. (2000). The scientific status of projective techniques. Psychological Science in the Public Interest, 1, 27-66.

Little, B. R. (1983). Personal projects: A rationale and method for investigation. Environment and Behavior, 15, 273-309.

Logan, G. D., Schachar, R. J., \& Tannock, R. (1997). Impulsivity and inhibitory control. Psychological Science, 8, 60-64.

Mayer, J. D. (1995). A framework for the classification of personality components. Journal of Personality, 63, 819-877.

McAdams, D. P. (1993). The stories we live by: Personal myths and the making of the self. New York: William Morrow.

McAdams, D. P. (1996). Personality, modernity and the storied self: A contemporary framework for studying persons. Psychological Inquiry, 7, 295-321.

McAdams, D. P. (1999). The psychology of life stories. Review of General Psychology, 5, 100-122.

McAdams, D. P., Reynolds, J., Lewis, M., Patten, A., \& Bowman, P. ( 2001). When bad things turn good and 
good things turn bad: Sequences of redemption and contamination in life narratives and their relation to psychosocial adaption in midlife adults and in students. Personality and Social Psychology Bulletin, 27, 474-485.

McClelland, D. C. (1987). Motive dispositions: The merits of operant versus respondent measures. In L. Wheeler (Ed.), Review of personality and social psychology (Vol. 1, pp. 11-41). Beverly Hills, CA: Sage.

McClelland, D. C., Koestner, R., \& Weinberger, J. (1989). How do self-attributed and implicit motives differ? Psychological Review, 96, 690-702.

Meyer, G. J., Finn, S. E., Eyde, L. D., Day, G. G., Moreland, K. L., Dies, R. R., et al. (2001). Psychological testing and psychological assessment. American Psychologist, 56, 128-165.

Mezzacappa, E., Kindoln, D., \& Earls, F. (2001). Child abuse and performance task assessments of executive functions in boys. Journal of Child Psychology $\mathcal{E}$ Psychiatry \& Allied Disciplines, 42, 1041-1048.

Murray, H. A. (1938). Explorations in personality. New York: Oxford University Press.

Ozer, D. J. (1986). Consistency in personality. Berlin, Germany: Springer Publishing Company.

Pals, J. L. (2005). Transforming the self: A two-dimensional process model of identity construction within narratives of difficult life events. Manuscript in preparation.

Paulhus, D. L., \& Harms, P. D. (2004). Measuring cognitive ability with the overclaiming technique. Intelligence, 32, 297-314.

Paulhus, D.L., Lysy, D., \& Yik, M. S M. (1998). Self-report measures of intelligence: Are they useful as proxy measures of IQ? Journal of personality, 66, 525554.

Pennebaker, J. W., \& Francis, M. E. (1996). Cognitive, emotional and language processes in disclosure. Cognition and Emotion, 10, 601-626.

Roberts, B. W., \& Caspi, A. (2003). The cumulative continuity model of personality development: Striking a balance between continuity and change in personality traits across the life course. In R. M. Staudinger \& U. Linderberger (Eds. ), Understanding human development: Lifespan psychology in exchange with other disciplines (pp. 183-214). Dorecht, the Netherlands: Kluwer Academic Publishers.

Roberts, B. W., \& DelVecchio, W. F. (2000). The rankorder consistency of personality traits from childhood to old age: A quantitative review of longitudinal studies. Psychological Bulletin, 126, 3-25.

Roberts, B. W., \& Pomerantz, E. M. (in press). On traits, situations and their integration: A developmental perspective. Personality and Social Psychology Review.
Roberts B. W., \& Robins, R. W. (2000). Broad dispositions, broad aspirations: The intersection of personality traits and major life goals. Personality and Social Psychology Bulletin, 26, 1284-1296.

Roberts, B. W., \& Wood, D. (in press). Personality development in the context of the neo-socioanalytic model of personality. In D. Mroczek \& T. Little (Eds.), Handbook of personality development. Mahwah, NJ: Lawrence Erlbaum Associates.

Roberts, B. W., Bogg, T., Walton, K., Chyernyshenko, O. S., \& Stark, S. (2004). A lexical approach to identifying the lower-order structure of conscientiousness. Journal of Research in Personality, 38, 164-178.

Rolfhus, E., \& Ackerman, P. L. (1999). Assessing individual differences in knowledge: Knowledge, intelligence, and related traits. Journal of Education Psychology, 91, 511-526.

Rorer, L. G. (1965). The great response-style myth. Psychological Bulletin, 63, 129-156.

Schmalt, H. (1999). Assessing the achievement motive using the grid technique. Journal of Research in Personality, 33, 109-130.

Schwarz, N., \& Bells, H. (1992). Constructing reality in social judgment. In L. L. Martin \& A. Tesser (Eds.), The construction of social judgments (pp. 217-245). Hillsdale, NJ: Lawrence Erlbaum Associates.

Smith, C. P. (Ed.). (1992). Motivation and personality: Handbook of thematic content analysis. Cambridge, MA: Cambridge University Press.

Spain, J. S., Eaton, L. G., \& Funder, D. C. (2000). Perspective on personality: The relative accuracy of self versus others for the prediction of emotion and behavior. Journal of Personality, 68, 837-867.

Spangler, W. D. (1992). Validity of questionnaire and TAT measures of need for achievement: Two metaanalyses. Psychological Bulletin, 112, 140-154.

Winter D. G., John, O. P., Stewart, A. J., Klohen E. C., \& Duncan, L. E. (1998). Traits and motives: Toward an integration of two traditions in personality research. Psychological Review, 105, 230-250.

Winter, D. G. (1991). Measuring personality at a distance: For scoring motives in running text. In A. J. Stewart, J. M. Healy Jr., \& D. J. Ozer (Eds.), Perspectives in personality: Approaches to understanding lives (Vol. 3, pp. 59-89). London: Jessica Kingsley Publishers.

Wirtz, D., Kruger, J., Napa-Scollon, C., Diener, E. (2003). What to do on spring break? The role of predicted, on-line, and remembered experience in future choice. Psychological Science, 14, 520-524. 